Jul 1st, 12:00 AM

\title{
MOIRA-PLUS: a decision support system for the management of complex fresh water ecosystems contaminated by radionuclides and heavy metals
}

Luigi Monte

Lars Håkanson

D. Hofman

John Brittain

Eduardo Gallego

See next page for additional authors

Follow this and additional works at: https://scholarsarchive.byu.edu/iemssconference

Monte, Luigi; Håkanson, Lars; Hofman, D.; Brittain, John; Gallego, Eduardo; Jimenez, Antonio; and Angeli, Giacomo, "MOIRA-PLUS: a decision support system for the management of complex fresh water ecosystems contaminated by radionuclides and heavy metals" (2006). International Congress on Environmental Modelling and Software. 100.

https://scholarsarchive.byu.edu/iemssconference/2006/all/100

This Event is brought to you for free and open access by the Civil and Environmental Engineering at BYU ScholarsArchive. It has been accepted for inclusion in International Congress on Environmental Modelling and Software by an authorized administrator of BYU ScholarsArchive. For more information, please contact scholarsarchive@byu.edu, ellen_amatangelo@byu.edu. 


\section{Presenter/Author Information}

Luigi Monte, Lars Håkanson, D. Hofman, John Brittain, Eduardo Gallego, Antonio Jimenez, and Giacomo Angeli

This event is available at BYU ScholarsArchive: https://scholarsarchive.byu.edu/iemssconference/2006/all/100 


\title{
MOIRA-PLUS: a decision support system for the management of complex fresh water ecosystems contaminated by radionuclides and heavy metals
}

\author{
L. Monte, ENEA, Italy \\ L. Håkanson, Uppsala University, Sweden \\ D. Hofman, Studsvik Nuclear AB, Sweden \\ J. E. Brittain, University of Oslo, Norway \\ E. Gallego, A. Jiménez, Universidad Politécnica de Madrid, Spain \\ G. Angeli, ENEA, Italy
}

\begin{abstract}
The accidental release of radioactive substances into the environment leads to the necessity of applying suitable countermeasures for the restoration of the polluted environment. However, despite their obvious benefits, such interventions may result in detrimental effects of economic, ecological and social nature that must be carefully evaluated.
\end{abstract}

MOIRA-PLUS is a PC-based user-friendly, Computerised Decision Support System (CDSS) that helps decision makers to choose optimal countermeasure strategies for different kinds of aquatic ecosystems and contamination scenarios.

CDSS MOIRA-PLUS is based on:

a) Validated models to evaluate the behaviour of radionuclides in contaminated water bodies and biota and to assess the effect of countermeasures on the contamination levels;

b) Models to assess the radiation dose to people and biota (fish) by the relevant exposure pathways, the effect of countermeasures, and the associated economic impact;

c) Multi-Attribute value Analysis (MAA) module to assess the effectiveness of different management strategies by accounting for the social, the ecological and economic detriments and costs in relation to their benefits.

The flexible structures of the environmental models implemented in MOIRA-PLUS allow the application of these models to several other types of pollutants, such as heavy metals. The CDSS can be applied to complex water systems comprised of lakes, reservoirs and rivers. The main principles underpinning the functioning of the CDSS MOIRA-PLUS will be described and discussed.

\section{Introduction}

The appropriate management of polluted fresh water ecosystems requires the assessment of the costs and the benefits of feasible restoration strategies. Any environmental intervention may cause, indeed, non-desirable effects of ecological, economic and social nature. Consequently, critical evaluations of alternative management strategies are necessary to determine which of these achieve the optimal balance between the related benefits and costs.

Such an evaluation requires two sets of tools:

a) Models for predicting the behaviour of contaminants in the fresh water environment, the effects of the countermeasure/restoration interventions on the levels of pollution and the ecological, the social and the economic impacts of such interventions; 
b) Methodologies for ranking the different applicable management strategies according to their effectiveness when the benefits and the detriments or costs of ecological, social and economic nature are accounted for.

For such purposes, it is necessary to manage a great deal of data and information. The Computerised Decision Support Systems (CDSS) MOIRA-PLUS (a Model-based computerised system for management support to Identify optimal remedial strategies for Restoring radionuclide contaminated Aquatic ecosystems and drainage areas) is a response to these needs (Appelgren et al., 1996; Brittain et al., 1999).

MOIRA-PLUS is a CDSS specifically designed for assisting experts to assess the appropriateness of suitable strategies for the management of aquatic ecosystems contaminated by radionuclides (Monte et al., 1999). The environmental models in MOIRAPLUS can be also used for predicting the behaviour of heavy metals in complex fresh water systems. The aim of the present work is to describe the main features and functionality of MOIRA-PLUS.

\section{General description of MOIRA-PLUS functioning principles}

MOIRA-PLUS is based on:

- Validated environmental models;

- A Multi-Attribute Analysis module for ranking the different feasible management strategies;

- Software components realising the models, joining all the CDSS components into the unit system and supporting the system with a user-friendly interface;

- Data storage and analysis tools (GIS and data bases).

The CDSS allows the user to run the models, to define possible restoration or countermeasure strategies, to rank the strategies according to their global effectiveness and to produce a report of the results. The MOIRA-PLUS system is intended to be: a) synthetic, that is knowledge is included and processed in the system in a structured manner; b) accessible, so that the information in the system will be found and used simply and rapidly; c) flexible and extensible so that new knowledge and models can be included as they become available.

\section{The MOIRA-PLUS models for predicting the environmental behaviour of contaminants}

The environmental models implemented in the MOIRA-PLUS CDSS were copiously described in the scientific literature (Håkanson, et al. 2004; Håkanson, 1999, 2000, 2005; Monte \& Brittain, 1998; Monte, 2001).

The models are intentionally not very complex, but comparatively small and general. They are driven by readily accessible environmental parameters from European databases and GIS-systems. The models are often based on "collective parameters" (Monte, 1996; Håkanson, 1995). The values of such parameters integrate many compensatory effects occurring in the very complex ecosystem where "everything depends on everything else" (Håkanson and Peters, 1995). 
MOIRA-PLUS includes models for lakes and complex fresh water systems. These models simulate: a) the time behaviour of the hydrological, morphologic and environmental quantities and of the migration parameters of contaminants through the water ecosystems; $b$ ) the migration of pollutants from the catchment to the aquatic system; c) the migration of pollutants through the abiotic components of the aquatic system; d) the migration of radionuclides from the abiotic components to the fishes species.

Complex fresh water systems, such as large rivers, are assumed to be composed of a chain of interconnected "elementary segments (ES)" that are comprised of: a) the water column; b) an upper sediment layer strongly interacting with water ("interface layer); c) an intermediate sediment layer below the "interface layer" ("bottom sediment"); d) a sink sediment layer below the "bottom sediment"; e) the right and left sub-catchments of each ES.

\section{Assessing the countermeasure effectiveness}

\subsection{Countermeasures}

In the event of radioactive contamination of aquatic ecosystems and their drainage areas there are a number of options available to management. The options are wide-ranging, from specific chemical treatment of water bodies to bans on fish ingestion or on the use of water for crops irrigation. The potential actions can be broadly grouped into four main categories, chemical, biological, physical and social. In some cases a combination of actions may be the optimal strategy,

4.2 The Multi-Attribute Analysis (MAA) module of MOIRA-PLUS is based on three main objectives: the ecological, the social and the economic impacts of the countermeasures (Fig. 1). The attributes, which indicate the degree to which objectives are achieved, are either selected from existing measures, such as cost or manpower, or constructed for the specific situation, such as indices of environmental impact. The decision process is therefore driven by appropriate utility functions that allows the ranking of different countermeasure options.

\subsection{The ecological Impact}

MOIRA-PLUS Ecosystem Index for lakes (LEI) is a powerful quantitative methodology to measure the ecological impact of countermeasures on aquatic ecosystems. LEI is a tool to give an holistic account for the environmental consequences of chemical remedial measures (lake and wet land liming, potash treatment and lake fertilisation) carried out to reduce radionuclide levels in water and biota. It should be stressed that any approach to determine how a given complex lake ecosystem would respond to different countermeasures by necessity involves many uncertainties (for further comments on these matters, see Håkanson and Peters, 1995). The lake ecosystem index used in the MOIRA system is intentionally simple. The first step in determining a LEI-value is to set normal or initial values of two important limnological state variables, $\mathrm{pH}$ and total-P. The second step involves predicting indices describing the abundance of key functional groups (the fish yield and biomasses of phytoplankton and bottom fauna). The third step concerns the evaluation of LEI. The method is fully described and motivated in the literature (Håkanson and Peters, 1995; Håkanson et al. 2000). 


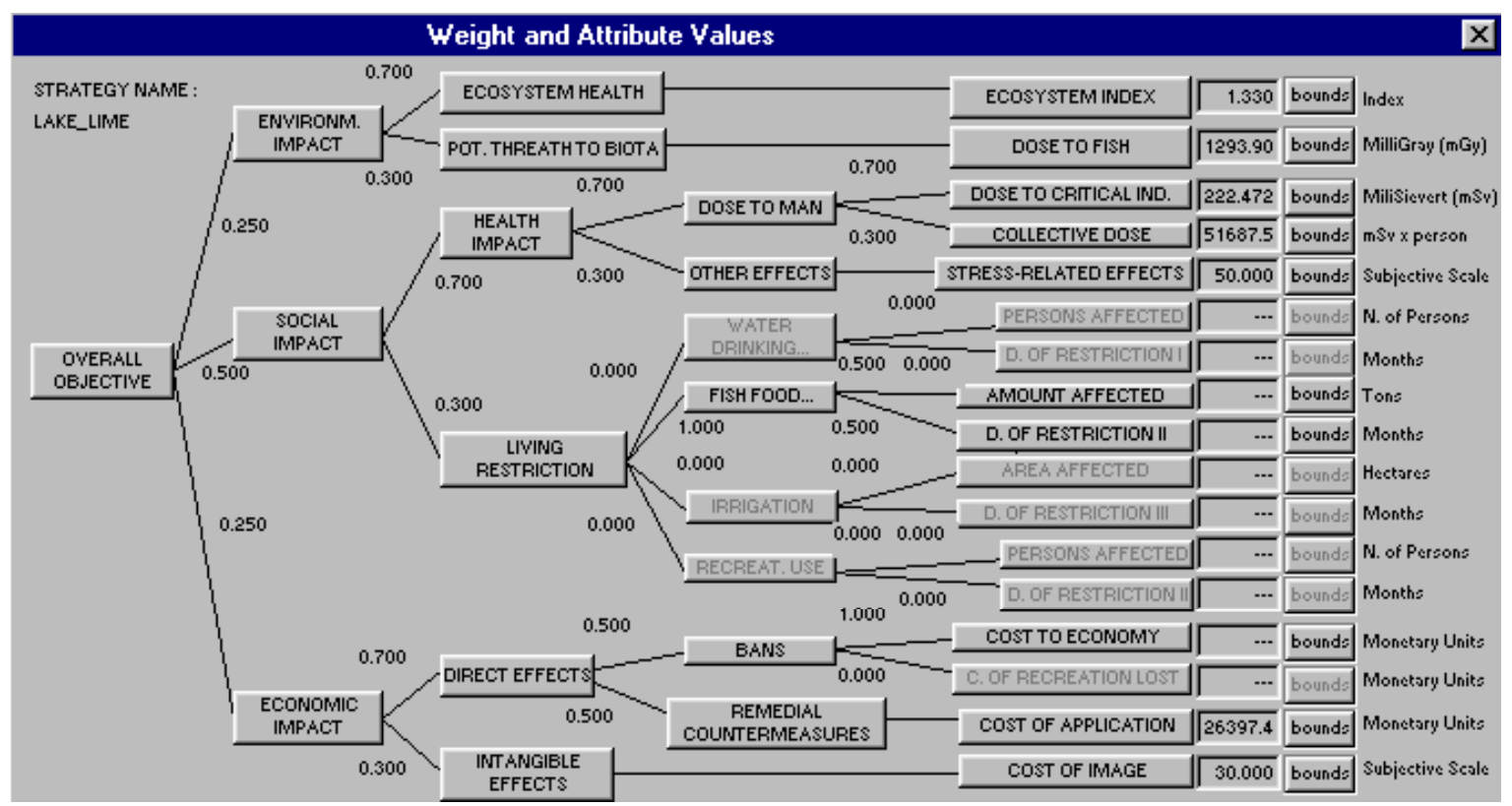

Figure 1. Tree of objectives considered for MAA in the MOIRA system: The overall objective is to minimise the environmental, social and economic impacts; each of them is split into different sub-objectives. At the lowest level the objectives can be measured in terms of attributes that are quantified with the system models.

The LEI is defined as:

$$
\mathrm{LEI}=(\mathrm{FYR}+\mathrm{PBR}+\mathrm{BFBR}) / 3
$$

where: a) FYR is the fish yield ratio reflecting the status of fish (mg ww/m².yr); b) PBR is the phytoplankton biomass ratio; c) BFBR is the bottom fauna biomass ratio. Each of the above parameters refers to the ratio between the quantity following the countermeasure application and the normal value in non-perturbed conditions. The interpretation of the fish yield ratio is that the value is 1 for a normal lake. A ratio of 2 means that the fish yield is 2 times higher than the normal. The same approach is used for the plankton biomass index and the bottom fauna biomass index. The evaluations of FYR, PBR and BFBR are done on the basis of quantitative relationships between these quantities and environmental variables like $\mathrm{pH}$ and total-P. Such empirical relationships were established by regression analysis of data collected in a number of lakes (Peters, 1986).

An additional attribute considered with respect to the environmental impact is the dose to fish (Higley et al. 2003; FASSET, 2004). Aquatic organisms in a radioactively contaminated environment will receive external exposure from radionuclides in the water and in the sediments; they will also receive internal exposure from nuclides accumulated in their tissues. This exposure may constitute a threat to biota present in aquatic ecosystems; in the MOIRA CDSS a simple model has been integrated to assess it.

\subsection{The social impact}

In the process of identifying the optimal remedial strategies after a radioactive contamination of aquatic ecosystems, social and economic factors may have a great importance. The social impact of countermeasures can be broadly linked to the health impact as well as to the alteration on normal living conditions of the population. Doses to man are a direct measure of the radiological impact of the radionuclides. On the other hand, less specific stress and reassurance-related effects that can result from the accident itself and from the application of countermeasures, are considered in a subjective, qualitative way. For 
those countermeasures implying restrictions in normal living conditions, the number of persons and the surface of the area affected by restrictions together with the duration of such restrictions are used to measure the social impact.

\subsection{The economic impact}

Standard methods for evaluating the different cost components of the application of countermeasures are employed. There exist a number of specific factors that could help to characterise the economic impact of a given countermeasure. Between these factors, some can be evaluated in terms of economic costs, like the following: a) man-power; b) equipments; c) consumables; d) duration implying impossibility of normal use of the element; e) cost of management and disposal of wastes generated; f) changes in the value of the element to be treated; g) changes in the amount and quality of production of the element.

\subsection{The MAA module}

The evaluation submodule of the MOIRA system (Ríos Insua et al., 2000, Ríos Insua et al., 2006) is based on a multi-attribute additive utility model. It includes facilities for assessing imprecise scalar utility functions and weighting factors, as well as a sensitivity analysis tool to check the sensitivity of the conclusions to the inputs, to allow the decision makers to gain insights into the problem.

\section{The Moira software}

MOIRA-PLUS software system guides the user from input handling, via execution of models, selection of remedial actions, evaluation of their ecological, economical and social consequences to result presentation and comparisons.

The general structure of MOIRA software system is shown in Figure 2.

The MOIRA-PLUS software system consists of the following parts: a) Software implementation of mathematical models; b) Software implementation of multiattribute analysis module; c) Geographical Information System (GIS) and Reference Data Base; d) MOIRA user interface; e) MOIRA Operating System

\section{The new features of MOIRA-PLUS}

The previous versions of the CDSS MOIRA were tested for many aquatic systems and assessed in the frame of international projects (Monte et al., 2001, Monte et al., 2005). Figure 3 and 4 show an example of an application to Po river (North Italy). Some of the described functionalities of MOIRA-PLUS were the results of improvements carried out following the experiences from the above activities of testing and assessment. In its present version, MOIRA-PLUS can be applied to aquatic systems with variable morphometry and can be used to predict the migration of heavy metals. The CDSS includes facilities for the sensitivity analysis of the results of the MAA module. The software interface of MOIRAPLUS was improved to make easier the input and the management of the great deal of data that are necessary for the applications to complex fresh water systems. 


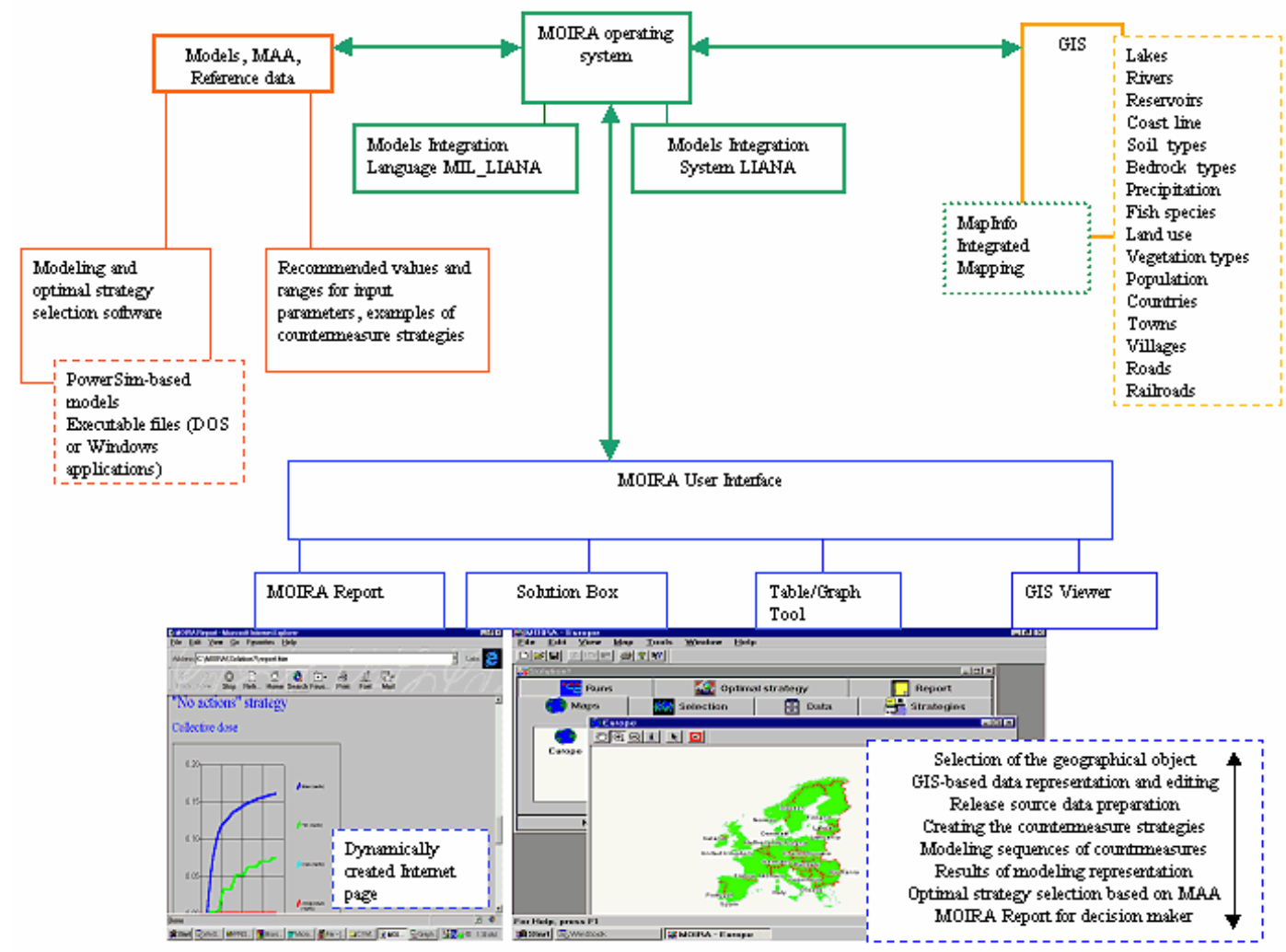

Figure 2. The structure of MOIRA software system

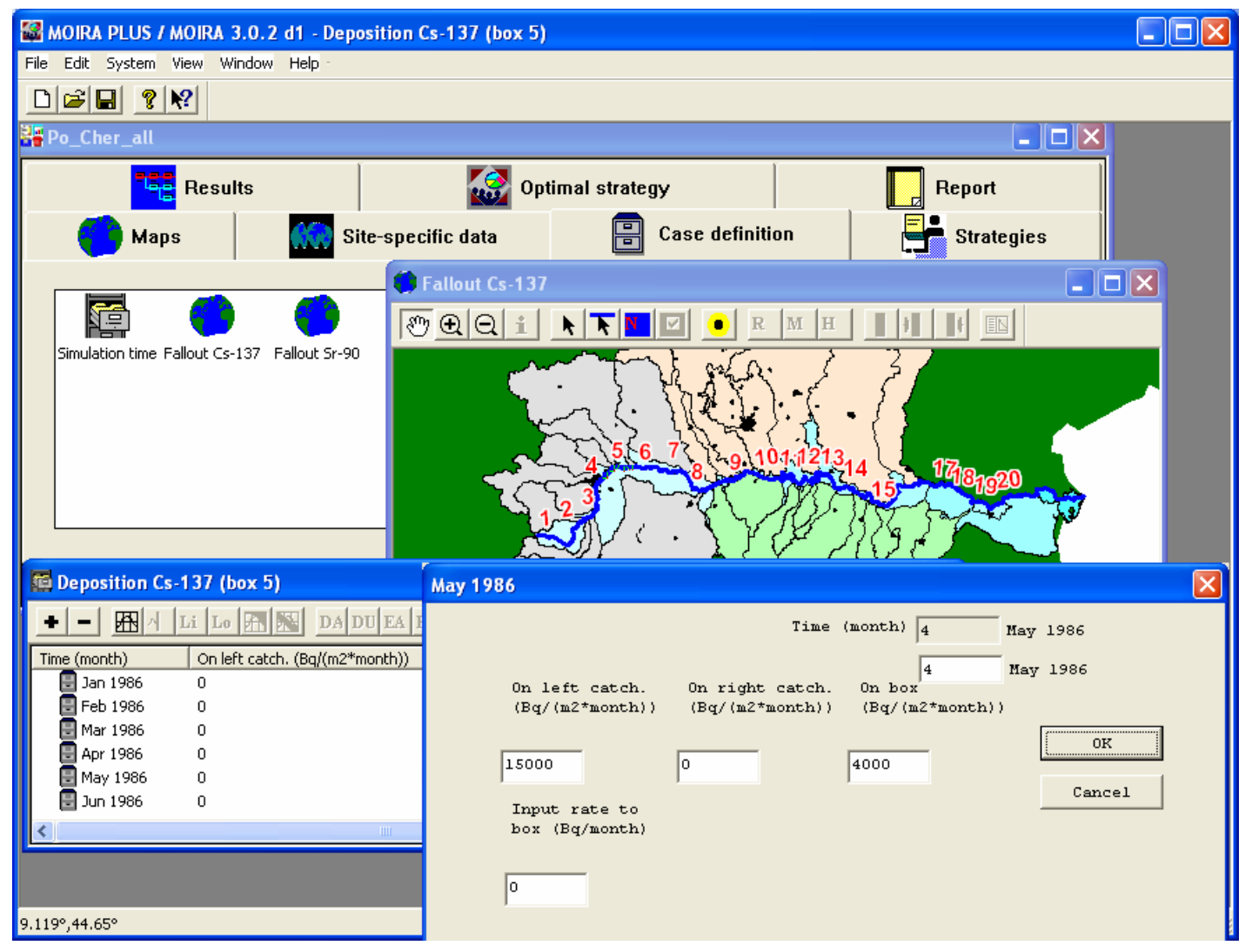

Figure 3.The window shows how MOIRA-PLUS manages the procedure for the data input. Po river was subdivided in 20 segments. It is possible to input contaminant deposition onto each segment and onto segment sub-catchments (left and right) of the river. 


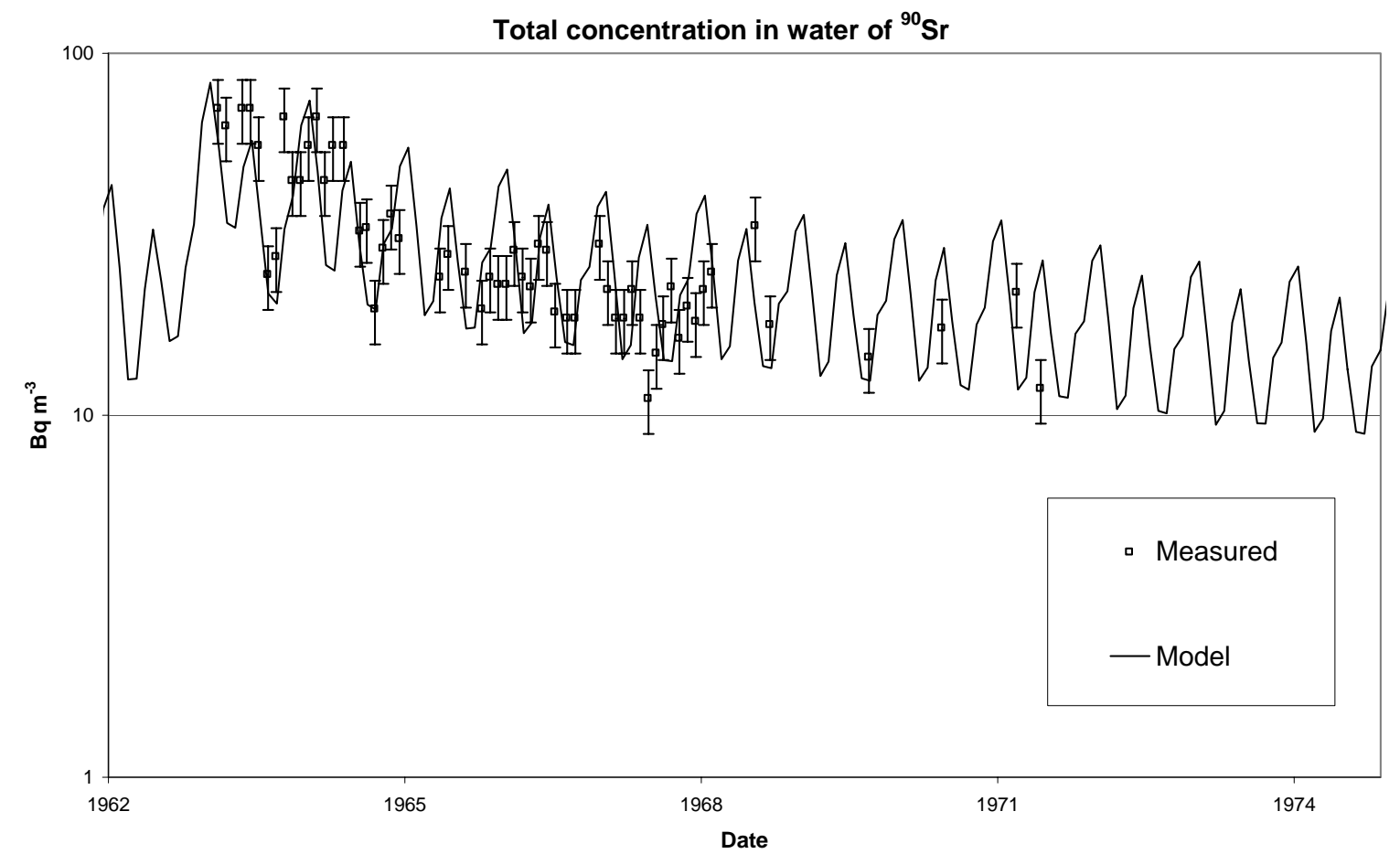

Figure 4. Application of MOIRA PLUS to river Po. Comparison of measured values of ${ }^{90} \mathrm{Sr}$ concentrations in water due the introduction in the environment of radionuclides from the nuclear weapon tests in atmosphere with the model results.

\section{Conclusions}

The MOIRA-PLUS software system is intended to be a user-friendly tool for decision makers that are responsible for the application of optimal restoration strategies to fresh water systems contaminated by radioactive substances. The migration models implemented in the DSS can be also applied to assess the migration of other pollutants, such as heavy metals, in complex fresh water systems.

MOIRA evaluates several types of countermeasures to reduce the dose via aquatic pathways, and advises the user the most effective method taking into account ecological, social and economic consequences. The use of the decision system MOIRA offers a quick insight in the effectiveness of countermeasures. The implementation of inappropriate and expensive countermeasures can be avoided by applying the MOIRA system.

Social, environmental and economic impacts are key points for decision-making on intervention strategies after radioactive contamination of the environment. MOIRA-PLUS system incorporates them into its MAA frame that allows considering these impact measures without converting them into monetary units.

MOIRA can be a helpful tool for different kind of users such as: a) Organisations responsible for maintaining the state-of-the-art knowledge in radioecology and in environmental protection, and b) Environmental protection agencies and administrators. Moreover MOIRA can be of great interest for educational institutions, such us universities. Therefore, the use of MOIRA software system may be of help to maintain a high technical level in environmental management. 


\section{References}

Appelgren, A., Bergström, U., Brittain,J., Gallego, E., Håkanson, L., Heling, R., Monte, L. 1996. An outline of a model-based expert system to identify optimal remedial strategies for restoring contaminated aquatic ecosystems: the project "MOIRA". RT/AMB/96/17, ENEA, Rome, Italy. 46 pp.

Brittain, J.E., Monte, L., Gallego Díaz, E., Håkanson, L., Heling, R. \& Hofman, D. 1999. The MOIRA project: methodologies for the development of a computerised decision support tool to restore radionuclide contaminated freshwater ecosystems. In: Strand, P. \& Jølle, T. (eds). Proceedings $4^{\text {th }}$ International Conference on Environmental Radioactivity in the Arctic, Edinburgh Scotland, September 1999, pp. 111-113.

FASSET, 2004. Framework for assessment of environmental impact (FASSET). Final report. Swedish Radiation Protection Authority, 111 pp.

Håkanson, L.1995. Optimal size of predictive models. Ecological Modelling, 78, 195204.

Håkanson, L., 1999. Modelling radiocesiumm in lakes and coastal areas - a textbook with Internet support. Kluwer Academic Publishers, Dordrecht, 215 p.

Håkanson, L. 2000. Modelling radiocaesium in lakes and coastal areas - new approaches for ecosystem modellers. A textbook with Internet support. Dordrecht: Kluwer Academic Publishers. 215 pp.

Håkanson, L., 2005. A new general mechanistic river model for radionuclides from single pulse fallouts which can be run by readily accessible driving variables. Journal of Environmental Radioactivity, 80, 357-382.

Håkanson, L. and Peters, R.H. 1995. Predictive limnology. Methods for predictive modelling. SPB Academic Publishing. The Netherlands. 464 pp.

Håkanson, L., Gallego, E. and Rios-Insua, S., 2000. The application of the lake ecosystem index in multi-attribute decision analysis in radioecology. Journal of Environmental Radioactivity, 49, 319-344.

Håkanson, L., Blenckner, T. and Malmaeus, J.M., 2004. New, general methods to define the depth separating surface water from deep water, outflow and internal loading for massbalance models for lakes. Ecological Modelling, 175, 339-352.

Higley, K.A., Domotor, S.L., Antonio, E.J., Kocher, D.C., 2003. Derivation of a screening methodology for evaluating radiation dose to aquatic and terrestrial biota. Journal of Environmental Radioactivity, 66, 41-59,

Monte, L. 1996. Collective models in environmental science. Sci. Tot. Environ., 192,41-47

Monte, L. 2001. A generic model for assessing the effects of countermeasures to reduce the radionuclide contamination levels in abiotic components of fresh water systems and complex catchments. Environmental Modelling and Software, 16, 669-690

Monte, L. and Brittain, J.E. (eds). 1998. Principles for the development and implementation of the MOIRA computerised system. ENEA report RT/AMB/98/4. 97 pp.

Monte, L., Brittain, J.E., Håkanson, L. and Gallego, E. (Eds) 1999. MOIRA models and methodologies for assessing the effectiveness of countermeasures in complex aquatic systems contaminated by radionuclides.. ENEA, RT/AMB/99/1, 150 pp.

Monte, L., Brittain, J. E., Håkanson, L., Gallego, E., Zheleznyak, M., Voitsekhovitch, O., Kryshev, I. and Marinov Petrov, K. (eds) 2001. Implementing computerised methodologies to evaluate the effectiveness of countermeasures for restoring radionuclide contaminated fresh water ecosystems. ENEA, RT/AMB/2001/28, 187 pp. 
Monte, L., Hofman, D. and Brittain, J. E. (eds) 2005. Evaluation and network of ECDecision Support Systems in the field of hydrological dispersion models and aquatic radioecological research. ENEA, RT/2005/49/PROT

Peters, R.H., 1986. The role of prediction in limnology. Limnol. Oceanogr. 31, 11431159.

Ríos Insua D., Gallego E, Mateos A and Rios-Insua S., 2000. MOIRA: A decision support system for decision making on aquatic ecosystems contaminated by radioactive fallout Annals of Operations Research, 95, 341-364

Ríos-Insúa, S., Gallego, E., Jiménez, A., Mateos, A., 2006. A Multi-Attribute Decision Support System for selecting intervention strategies for radionuclide contaminated freshwater ecosystems, Ecological Modelling (in press). 